\title{
The Impact of Climate Change on Material Degradation: Finding a Feasible Approach for Climate Model Evaluation
}

\section{Hamed Hedayatnia and Nathan Van Den Bossche}

\begin{abstract}
Building physics Group, Faculty of Engineering and Architecture Ghent University, 9000-Gent, Belgium, hamed.hedayatnia@ugent.be
\end{abstract}

\begin{abstract}
Understanding how climate change accelerates or slows down the process of material deterioration is the first step towards assessing adaptive approaches for the preservation of historical heritage. Analysis of the climate change effects on the degradation risk assessment parameters like freeze-thaw cycles and salt crystallization is also a key parameter when considering mitigating actions. Due to the vulnerability of cultural heritage in Iran to climate change, the impact of this phenomenon on basic parameters like temperature was analyzed. Choosing an appropriate regional climate model is the first and most crucial step in the analysis of climate change effects on heritage. The outputs of two different regional climate models: the ALARO-0-SURFEX model (Ghent University, Belgium) and the REMO model (HZG-GERICS, Germany) were analyzed to find out which model is more adapted to the region. So the focus of this research is mainly on the evaluation process to find a feasible approach for validation study to determine the reliability of each model. For model validation, a comparison between model data and observations was performed for 30 yearsfrom 1980-2017. Besides, some climatic parameters which are likely critical for heritage like freeze-thaw cycles were studied to find out how reliable these models are in the field of building pathology.
\end{abstract}

Keywords: Iran, Climate Change, Degradation Criteria, Heritage.

\section{Introduction}

The Iranian plateau hosts one of the world's oldest civilizations. The country's rich cultural heritage is reflected in part by its 22 UNESCO world heritage sites. The Iranian Plateau is one of the world's most mountainous countries, with a landscape dominated by rugged mountain ranges.

Having 11 climates (Figure 1) out of the world's 13, Iran's climate is diverse, ranging from arid and semi-arid, to subtropical along the Caspian coast and the northern forests.

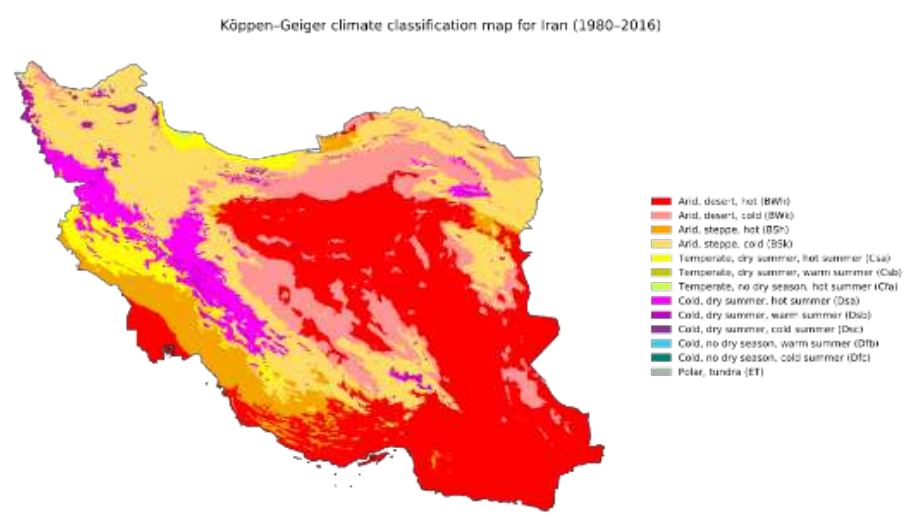

Figure 1.Climate map of Iran (Köppen-Geiger). 


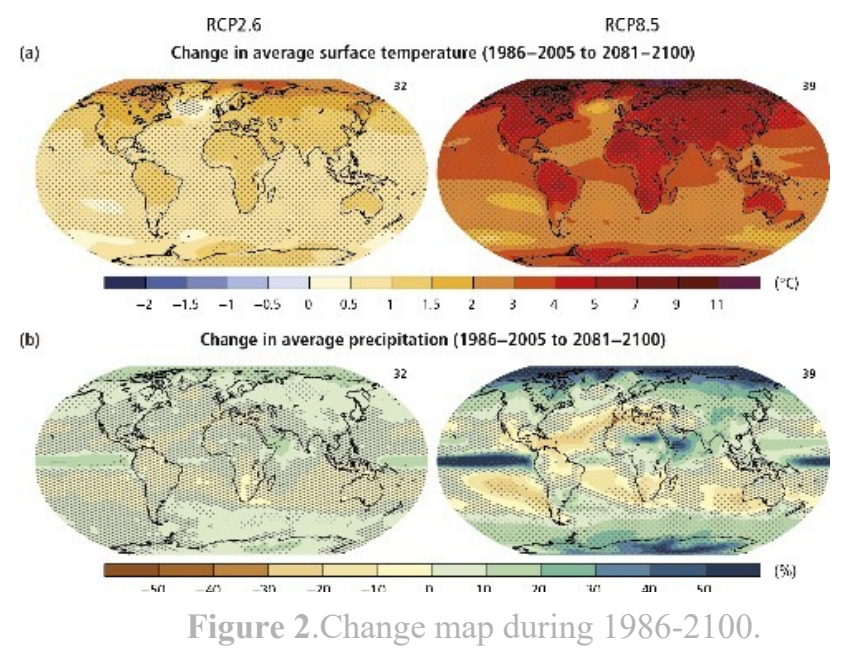

The Fifth Assessment Report of the Intergovernmental Panel on Climate Change suggests significant changes in climate conditions during the twenty-first century, such as drier and hotter summers over the middle East. Moreover, studies with different scenarios show that climate changes in Mediterranean Bassin are anticipated to exceed global mean values significantly (Giorgi 2006), and Iran is located in this region (Figure 2). Climate models are (Termonia, Schaeybroeck, De regional climate models are neet for this region.

Today there are on.y low-resolution data ava resolution (e.g. $25 \mathrm{~km}$ ) regional climate proj

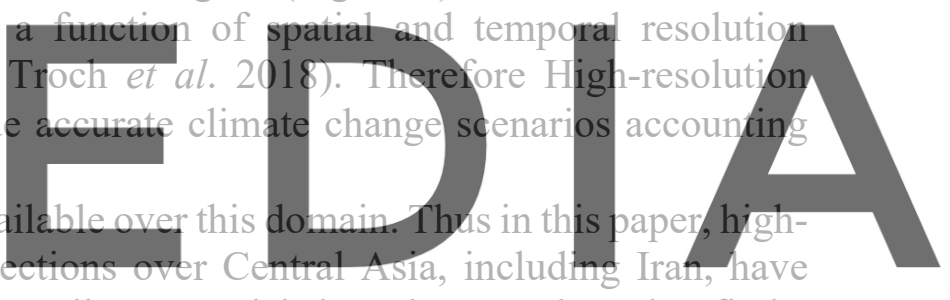
been analyzed. For more accuracy, two different climate models have been evaluated to find a

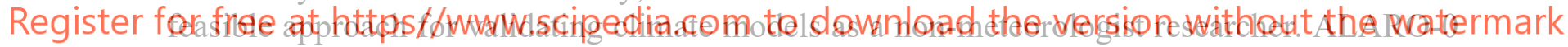
model (Ghent University, Belgium) and REMO (HZG-GERICS, Germany). Both models provide climate projections for the "21st" century following different RCP scenarios. These models need to be evaluated first. The RCM data in this analysis originates from the ALARO0 and REMO models at a spatial resolution of $25 \mathrm{~km}$ across the central Asia domain and timefrequency of 1-hour. The analyzed type of model run for both models is the evaluation run. This means that the lateral boundary conditions of the model, i.e. the Asian boundaries, are forced by reanalysis data. The evaluation run enables the possibility to evaluate whether the model is able to reproduce the weather conditions within the imposed boundaries conditions at given grid points.

To analyze the evaluation run of the models over the domain, four grid points located in different climate zones, were studied. A comparison is made with historical observations at the same locations using MATLAB. The discussed parameters are outdoor air temperature and relative humidity and precipitation. For each parameter, scatterplots of the observations and modelled data are produced, as well as distribution functions both based on hourly, daily, and monthly values. Through the validation study, some climatic parameters which are likely critical for heritage like freeze-thaw cycles and salt crystallization index were evaluated for both models in comparison with the historical data to find out how reliable these models are in the field of building pathology. 
In the case of temperature, relative humidity, and wind velocity, daily values represent daily averages, whereas, for precipitation, total daily values are considered. Furthermore, the root means square error (RMSE), correlations, adjusted R-squared, and regression are computed to find out the reliability of the models. The studied grid points are listed below:

Mashhad, which is located in the northeastern corner of Iran, features a steppe climate (Köppen/BSk) with hot summers and cold winters.

Shiraz is located in the south of Iran. Shiraz's climate is overall classified as a hot semi-arid climate (Köppen climate classification $B S h$ ).

Tabriz is located in the northwest of Iran has a humid continental climate with regular seasons (Köppen $D s a$ ) bordering Cold semi-arid climate (Köppen BSk).

Rasht is located on Iran's Caspian Sea coast, depending on the precipitation, Rasht either has a humid subtropical climate $(C f a)$ or a Mediterranean climate $(C s a)$.

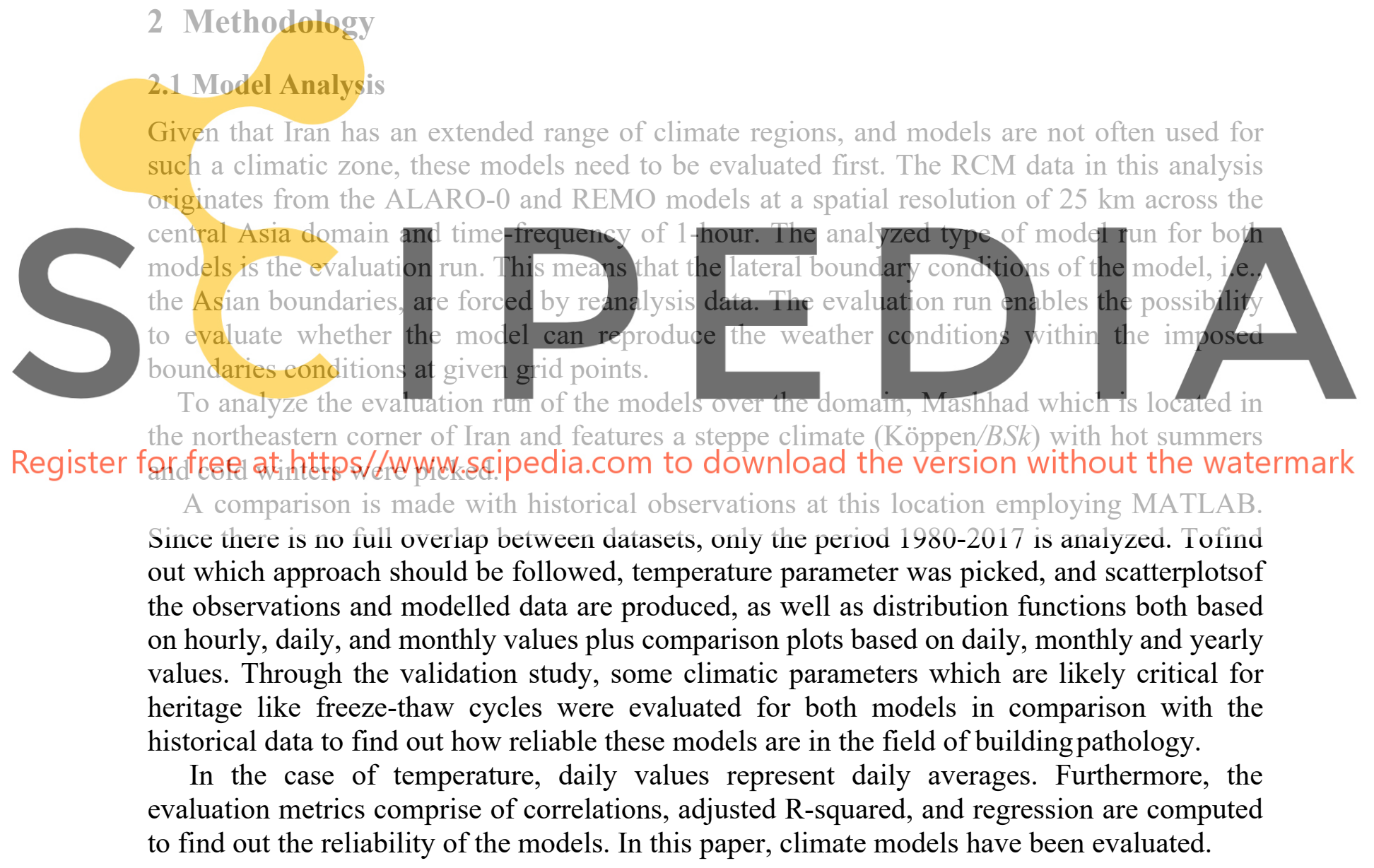




\subsubsection{Temperature Analysis}

The scatterplot of both models during the studied period (Figure 3 and 4) indicates that there is a good overall representation of the observed hourly outdoor air temperature $(\mathrm{T})$ by both models. The linear fit (red) of the hourly temperature almost follows the diagonal (perfect fit). The hourly temperature distribution of both datasets, i.e., the observations and the modeled data, confirms this statement. However, there is a slight bias towards colder temperatures by the ALARO-0 modelled data, and almost the same bias towards warmer temperatures by the REMO modelled data (Figure 5 and 6). In mid-range temperatures, models have different behaviours where ALARO-0 has an underestimation of mid-range temperatures, and REMO has an overestimation.
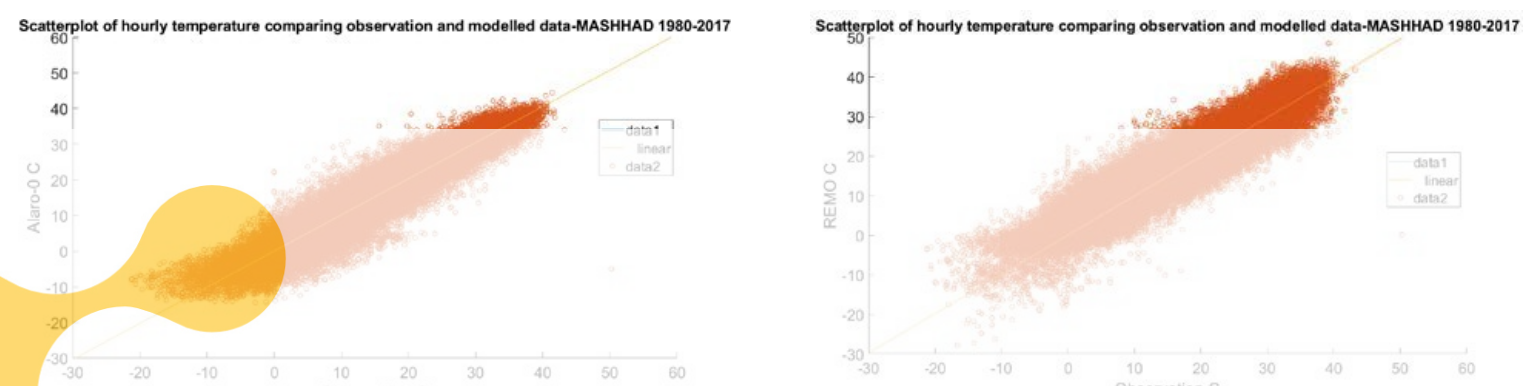

Figure 3. Hourly temperature scatterplot ALARO-0 model. Figure 4. scatterplot -Remo model(1980-2017).
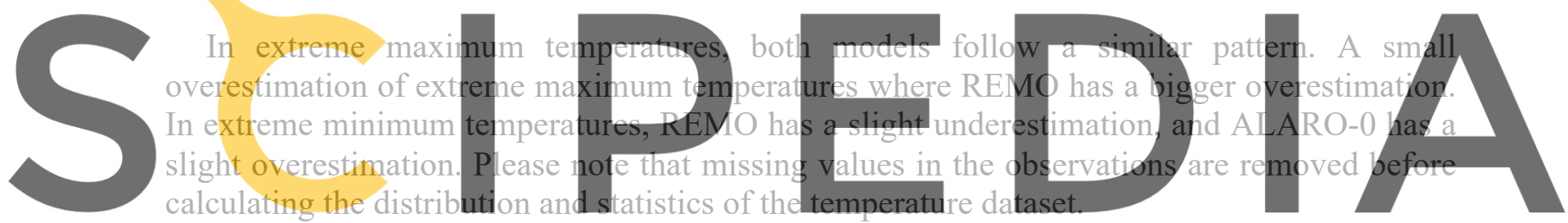

The observed Tmean over the whole dataset is $15.03^{\circ} \mathrm{C}$. For the ALARO-0, the Tmean is

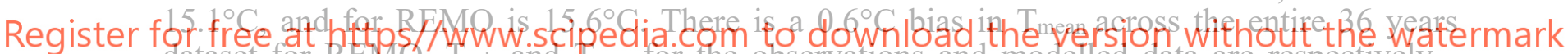
dataset for $\mathrm{REMO}$. T min and 1 max tor the observations and modelled data are respectively $21.2^{\circ} \mathrm{C}$ and $43.2^{\circ} \mathrm{C}$, and $-14.5^{\circ} \mathrm{C}$ and $44.5^{\circ} \mathrm{C}$ (ALARO-0) and $-28.8^{\circ} \mathrm{C}$ and $48.5^{\circ} \mathrm{C}(\mathrm{REMO})$.

These values are not in line with the conclusions based on the distribution, i.e., the underestimation of extreme minimum temperatures by REMO modelled data towards colder temperatures. However, as these values are outliers, they are not expected to represent the temperature distribution.

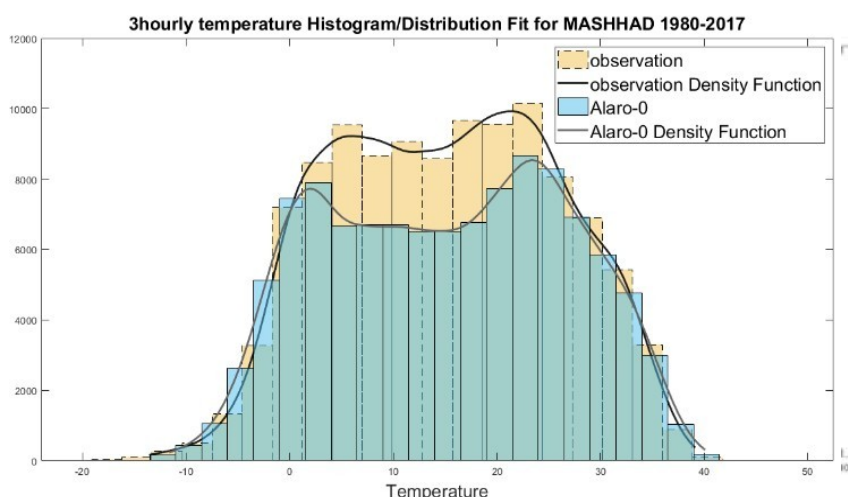

Figure 5.Hourly temperature Histogram ALARO-0. 3hourly temperature Histogram/Distribution Fit for MASHHAD 1980-2017

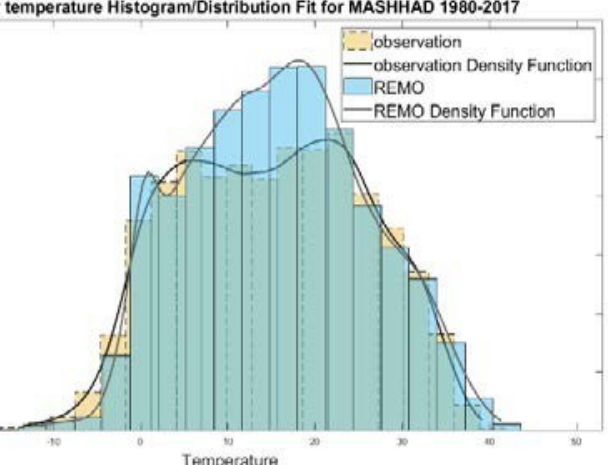

Figure 6.Hourly temperature Histogram REMO. 
By analysis of the monthly statistics (Figure 7), it can be observed that the monthly $\mathrm{T}_{\text {mean }}$, except the observation of summer months (higher temperatures), is lower than the REMO $\mathrm{T}_{\text {mean }}$ in all months. On the other hand, except winter months, the monthly $\mathrm{T}_{\text {mean }}$ of the observations is lower than the $\mathrm{T}_{\text {mean }}$ of the ALARO-0 model. Moreover, the absolute $\mathrm{T}_{\max }$ of the observations, every month except for August is lower than $\mathrm{T}_{\max }$ of the REMO. Whereas the observations and ALARO- 0 model in this value are very consistent almost every month, the observed absolute $\mathrm{T}_{\min }$ is lower than the ALARO-0 modeled temperature when the $\mathrm{T}_{\min }$ is

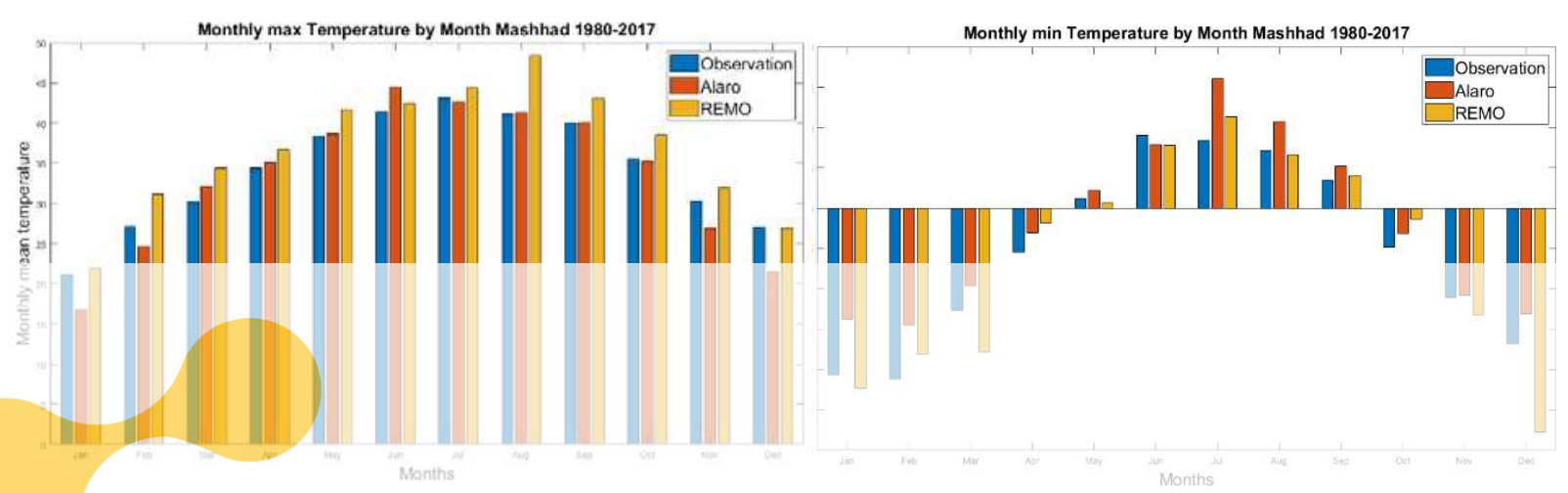

below $0^{\circ} \mathrm{C}$.

Figure 7. Comparison between monthly min and max temperature of observation and model data.
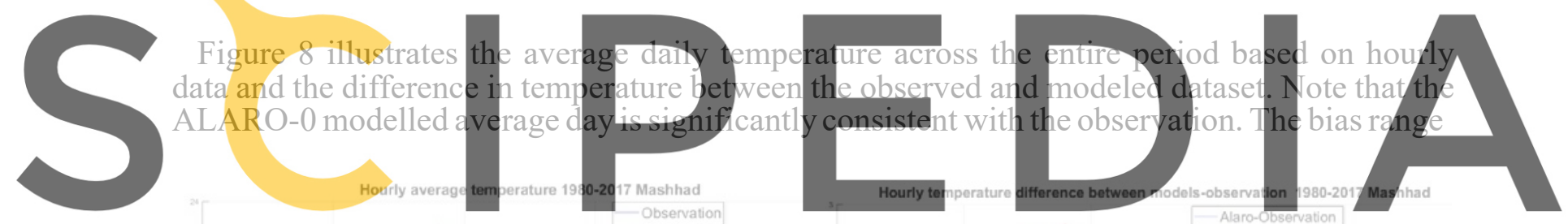

-ALARO

Register for free at https//www.scipedia.com to download the version without the watermark

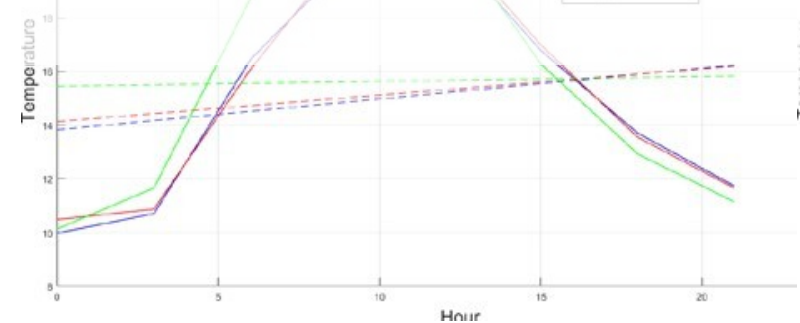

Figure 8. Plot based on hourly temperature.

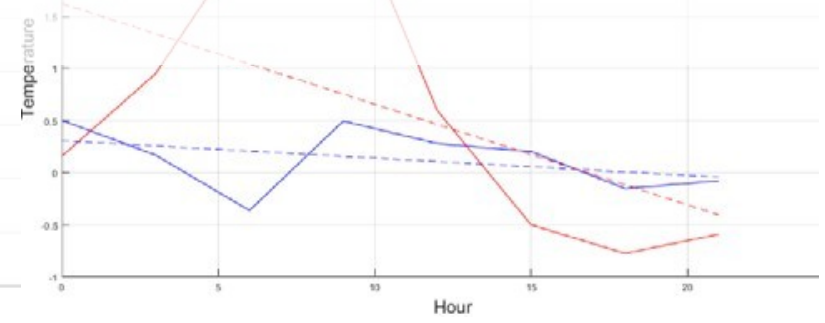

Figure 9. Difference between the datasets temperature.

is between -0.3 and $+0.5^{\circ} \mathrm{C}$ (Figure 9), respectively, at 6 am, and 9 am, whereas, in the REMO model, more bias is observed mainly during the first hours of the day before $10 \mathrm{am}$. Biased for every hour, ranging between -0.7 and $+2.7{ }^{\circ} \mathrm{C}$, respectively, at $6 \mathrm{pm}$ and $9 \mathrm{am}$. The most substantial temperature difference is observed in the morning for both models. This could be related to the location of the station, which is located in a semi-arid area, and an essential specification of this climate area is a vast difference between temperature in day and night, and perhaps the REMO model does not capture this effect accurately.

The distributions of daily $\mathrm{T}_{\text {mean }}$ is provided per season (Figure10). Interestingly, both models show the same results. The most significant difference in distribution between the observations and both models is found in summer, whereas smaller differences characterize spring. 

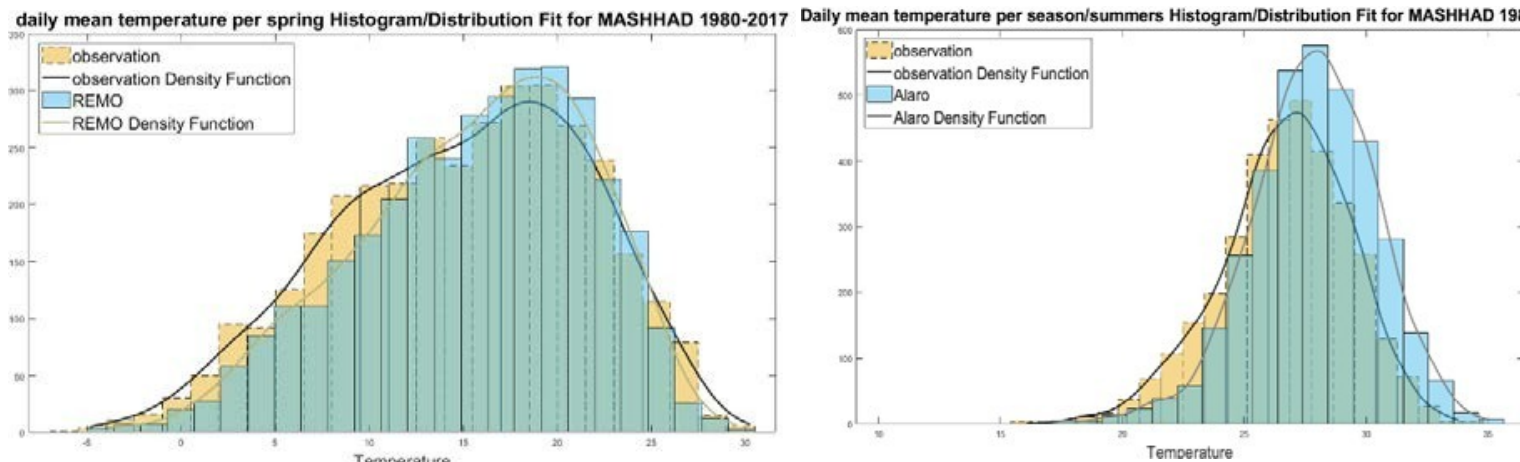

Figure 10. Seasonal temperature comparison between the distribution of the ALARO-0\&REMO models.

Besides statistics on hourly and daily $\mathrm{T}_{\text {mean }}$, some unusual indices are useful in the field of building physics, such as indices on frost. The first discussed index is the number of freezethaw cycles (FTC) as described by Grossi et al. (2007), referred to as criterion 1.

Based on daily $\mathrm{T}_{\text {mean, }}$, one cycle is counted each time the temperature drops below $0^{\circ} \mathrm{C}$, given that the previous day was a non-freezing day. Following, the difference in the annual number of FTC between the observations and the modeled data is computed. It can be noted that unlike the observations, both models follow an increasing trend (Figure 11).

The hours of frost index, illustrated in Figure 12, indicate the annual duration of freezing temperatures. The RFiviO model has predicted considerably fewer frost hours in comparison with the ALARO-0 model and observations. models follow an increa
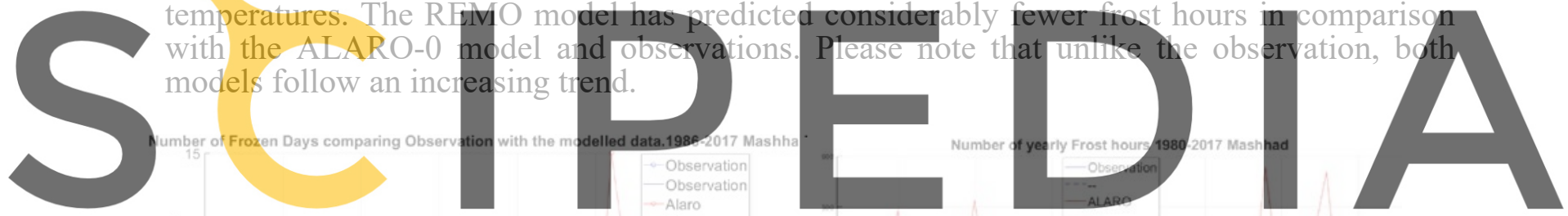

Register for free at https//www.scipedia.com to download the version without the watermark

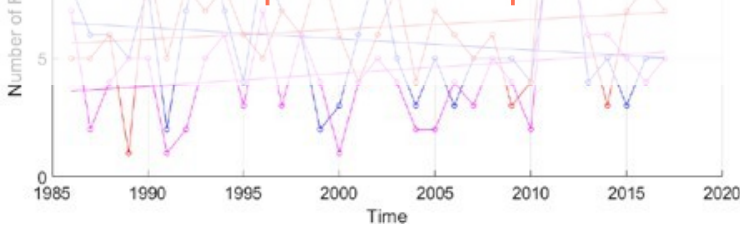

Figure 11. Number of FTC in models and observation.

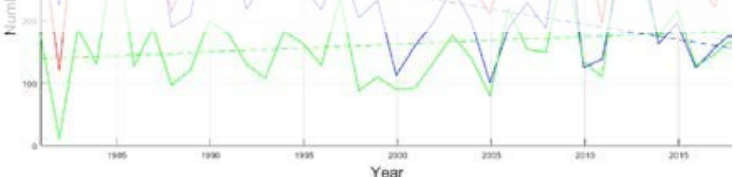

Figure 12. The number of frost hours per year.

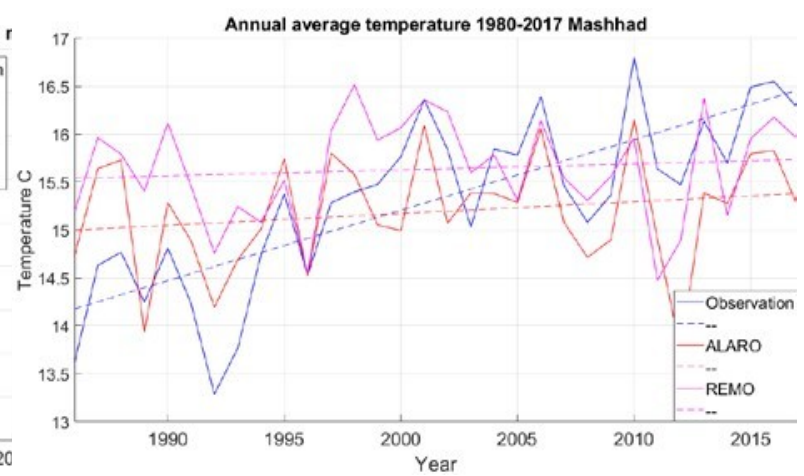

Figure 13. The number of wet-frost cycles. Mashhad. Figure 14. Annual average temperature, Mashhad. 
Previous indices are only based on temperature. However, frost damage in building envelopes is highly related to the moisture content in the porous media. The wet frost index considers the annual number of rainy days, i.e., the total daily precipitation exceeding $2 \mathrm{~mm}$ and temperatures higher than $0^{\circ} \mathrm{C}$, immediately followed by days having a $\mathrm{T}_{\text {mean }}$ below $-1{ }^{\circ} \mathrm{C}$ (Brimblecombe et al. 2006).

The wet frost index is generally higher for the ALARO-0 model compared to the REMO model and more consistent with the observation (Figure 13).

During the analysis of timetables, based on the yearly $T_{\text {mean }}$ (Figure 14) regarding the trendlines, it can be observed that the slope of both models similar to observation is incremental, but the real temperature rises at a higher rate. The studied city is the second biggest city in Iran, a dense metropolitan area. Given the existence of the well-known urban heat island phenomenon(UHI), this strong urbanization might Contribute to additional warming at this location, and models cannot catch it.

The evaluation metrics, which are essential in the model validation analysis, are computed (Table.1) and explained in the final part. The adjusted R-squared is a modified version of Rsquared that has been adjusted for the number of predictors in the model. An adjusted Rsquared of 1 means that the model ultimately predicts the studied parameter. Based on the above descriptions, the correlation, RMSE, and Adjusted R-Squared coefficient of both models indicate high accuracy, but the ALARO-0 model seems more reliable.

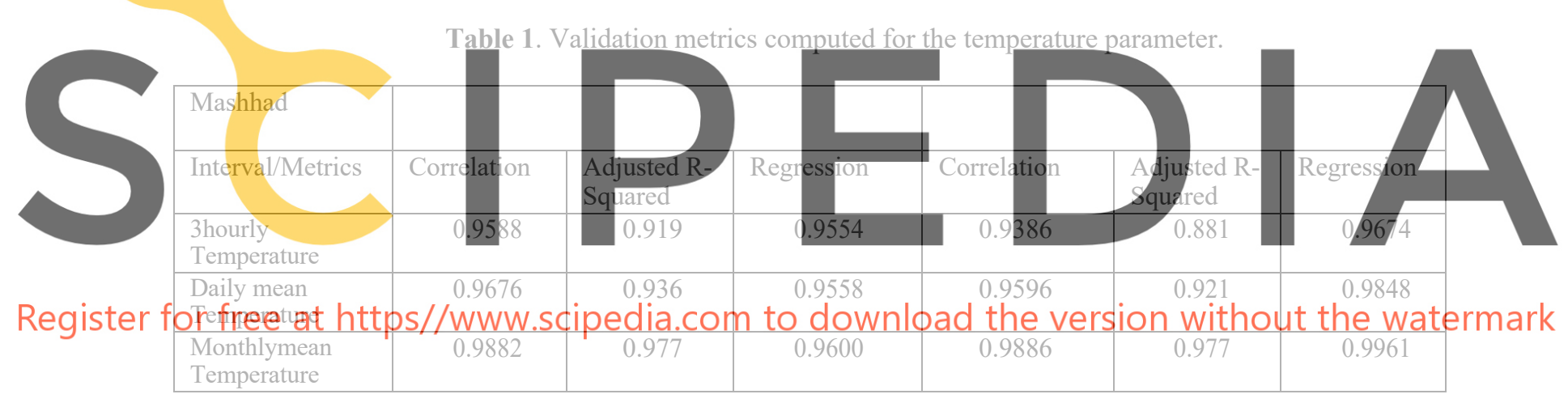

\section{Conclusions}

Regarding previous analysis and construing the figures and table of statistics, there can be concluded that the best approach for model validation is using the evaluation run of the model and comparing the model dataset with the historical observations in different parametersbased on hourly, daily and yearly time interval. Another critical issue that should be analyzed in each model validation study is considering relevant indexes to the research, i.e., freeze-thaw cycles, which are detrimental in building pathology in the current paper, should be analyzed. This method for our case study proved that both models based on temperature parameter are surprisingly accurate. Based on graphs construing and computed coefficients like correlation and adjusted R-squared, ALARO-0 model is a little more realistic and is suitable to use it as a reliable regional climate model over the target area. 


\section{Acknowledgement}

The RCM runs used in this paper have performed in the context of the AFTER project, which is granted by the ERA.Net RUS Plus Initiative, ID 166. The computational resources and services for the ALARO-0-0 regional climate simulations were provided by the Flemish Supercomputer Center (VSC), funded by the Research Foundation-Flanders(FWO) and the Flemish Government department EWI. The CORDEX-CORE REMO simulations were performed under the GERICS/HZG share at the German Climate Computing Centre (DKRZ). We would like to thank Steven Caluwaerts (UGent), Lola Kotova (GERICS), and Sara Top (UGent) for providing climate data.

\section{ORCID}

Nathan Van Den Bossche: https://orcid.org/0000-0002-8738-7249

Hamed Hedayatnia: https://orcid.org/0000-0002-9894-1217

\section{References}

Brimblecombe, P., Grossi, C.M. and Harris, I.(2006). Climate change critical to cultural heritage. In: Fort R, Álvarez de Buergo M, Gómez-HerasC, Vázquez-Calvo C, editors. Heritage, Weathering and Conservation. Rotterdam: Balkema, 387-93

Grossi, C.M., Brimblecombe, P. and Harris, I. (2007). Predicting Long Term Freeze-thaw Risks on Europe Built. Heritage and Archaeological sites in a Changing Climate. Science of the Total Environment, 377, $273-281$. Brimblecombe P, "The NOAH's ARK Project: The Impact of Future Climate Change on Cultural Heritage, The Eggs.Newsletter and Information Service of the EGU, no. 12, available at http://www.theeggs.org/articles.php?id=70

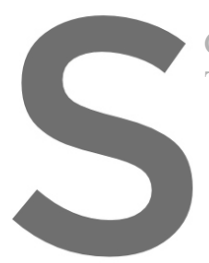

Giorgi, F.(2006). Climate

Termonia, P., Van Schaeybroeck, foundation for climate
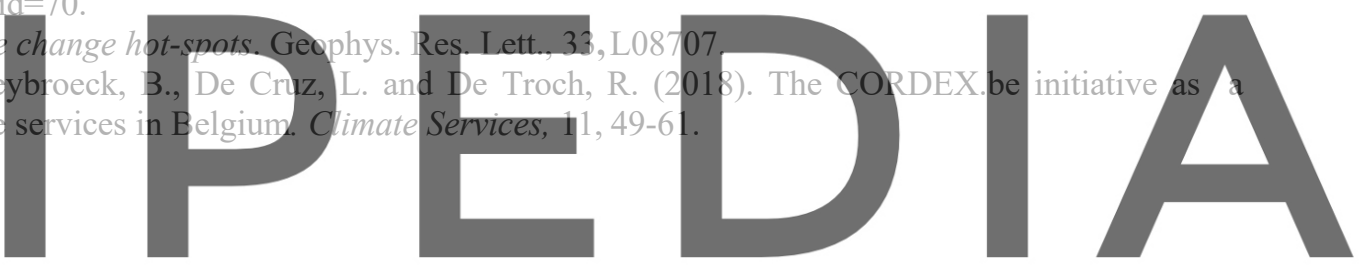

Register for free at https//www.scipedia.com to download the version without the watermark 